\title{
Unilateral Macular Lymphocytic Arteritis
}

ANA ARANA-GUAJARDO, MD, Servicio de Reumatología del Departamento de Medicina Interna, Hospital Universitario Dr. José Eleuterio González, Universidad Autónoma de Nuevo León, Monterrey, México; CYNTHIA MENDOZA-RODRÍGUEZ, MD, Servicio de Dermatología del Departamento de Medicina Interna, Hospital Universitario Dr. José Eleuterio González, Universidad Autónoma de Nuevo León, Monterrey, México; IVETTE MIRANDA-MALDONADO, MD, Servicio de Patología, Hospital Universitario Dr. José Eleuterio González, Universidad Autónoma de Nuevo León, Monterrey, México. Address correspondence to Dr. A. Arana-Guajardo, Servicio de Reumatología, Departamento de Medicina Interna, Hospital Universitario Dr. José Eleuterio González, Universidad Autónoma de Nuevo León, 235 Gonzalitos Avenue, Mitras Centro, C.P. 64020, Monterrey, México. E-mail: ana.aranag@gmail.com. J Rheumatol 2016;43:1763-4; doi:10.3899/jrheum.160240

Macular lymphocytic arteritis (MLA) is a benign cutaneous arteritis reported by Fein, et $a l^{1}$. MLA could be considered a non-nodule-forming variant or a less aggressive form of cutaneous polyarteritis nodosa $\mathrm{a}^{2,3}$.

A 23-year-old woman presented with an 8-week history of asymptomatic macular dermatosis located on the upper and lower right limbs (Figure 1). She denied fever, weight loss, animal bite, previous drug use, alopecia, visual disturbances, dry mouth, dyspnea, arthralgias, and gastrointestinal symptoms. Clinical examination was otherwise normal and lesions were asymptomatic. Routine laboratory tests, erythrocyte sedimentation rate, and C-reactive protein were in normal ranges. Tests were negative for antinuclear, anti-dsDNA, anti-SSA/Ro, anti-SSB/La, antiphospholipid, and antineutrophil cytoplasmic antibodies and complement factors. Skin biopsy from the right leg found vasculitis with fibrinoid necrosis associated with a perivascular lymphocytic infiltration affecting the arterioles at the dermal subcutaneous junction with negative immunofluorescence (Figure 2). We did not observe skin ulceration or internal elastic lamina disrupted in the affected vessels. Prednisone in low doses, methotrexate, and colchicine were used with total resolution of the lesions. After 8 months of followup, the patient was asymptomatic.

There is some controversy about the similarity of MLA with lymphocytic thrombophilic arteritis, with some authors considering them the same disease ${ }^{2,4}$. Saleh and Mutasim evaluated 10 cases of MLA with their clinical characteristics ${ }^{5}$. To our knowledge, ours is the only case with unilateral presentation. There is no standardized treatment regimen for MLA. Lee, et al had used various modalities such as prednisolone, low-dose aspirin, clopidogrel bisulfate, nifedipine, and warfarin 6 .

\section{REFERENCES}

1. Fein $\mathrm{H}$, Steth AP, Mutasim DF. Cutaneous arteritis presenting with hyperpigmented macules: macular arteritis. J Am Acad Dermatol 2003;49:519-22.

2. Macarenco RS, Galan A, Simoni PM, Macarenco AC, Tintle SJ, Rose R, et al. Cutaneous lymphocytic thrombophilic (macular) arteritis: a distinct entity or an indolent (reparative) stage of cutaneous polyarteritis nodosa? Report of 2 cases of cutaneous arteritis and review of the literature. Am J Dermatopathol 2013;35:213-9.

3. Buffiere-Morgado A, Battistella M, Vignon-Pennamen MD, de Masson A, Rybojad M, Petit A, et al. Relationship between cutaneous polyarteritis nodosa (cPAN) and macular lymphocytic arteritis (MLA): blinded histologic assessment of 35 cPAN cases J Am Acad Dermatol 2015;73:1013-20.

4. Kalegowda IY, Tirumalae R, Murthy KS, Rout P. Lymphocytic thrombophilic arteritis: an enigma. Indian J Dermatol 2014; 59:498-501.

5. Saleh Z, Mutasim DF. Macular lymphocytic arteritis: a unique benign cutaneous arteritis, mediated by lymphocytes and appearing as macules. J Cutan Pathol 2009;36:1269-74.

6. Lee JS, Kossard S, McGrath M. Lymphocytic thrombophilic arteritis: a newly described medium-sized vessel arteritis of the skin. Arch Dermatol 2008;144:1175-82. 


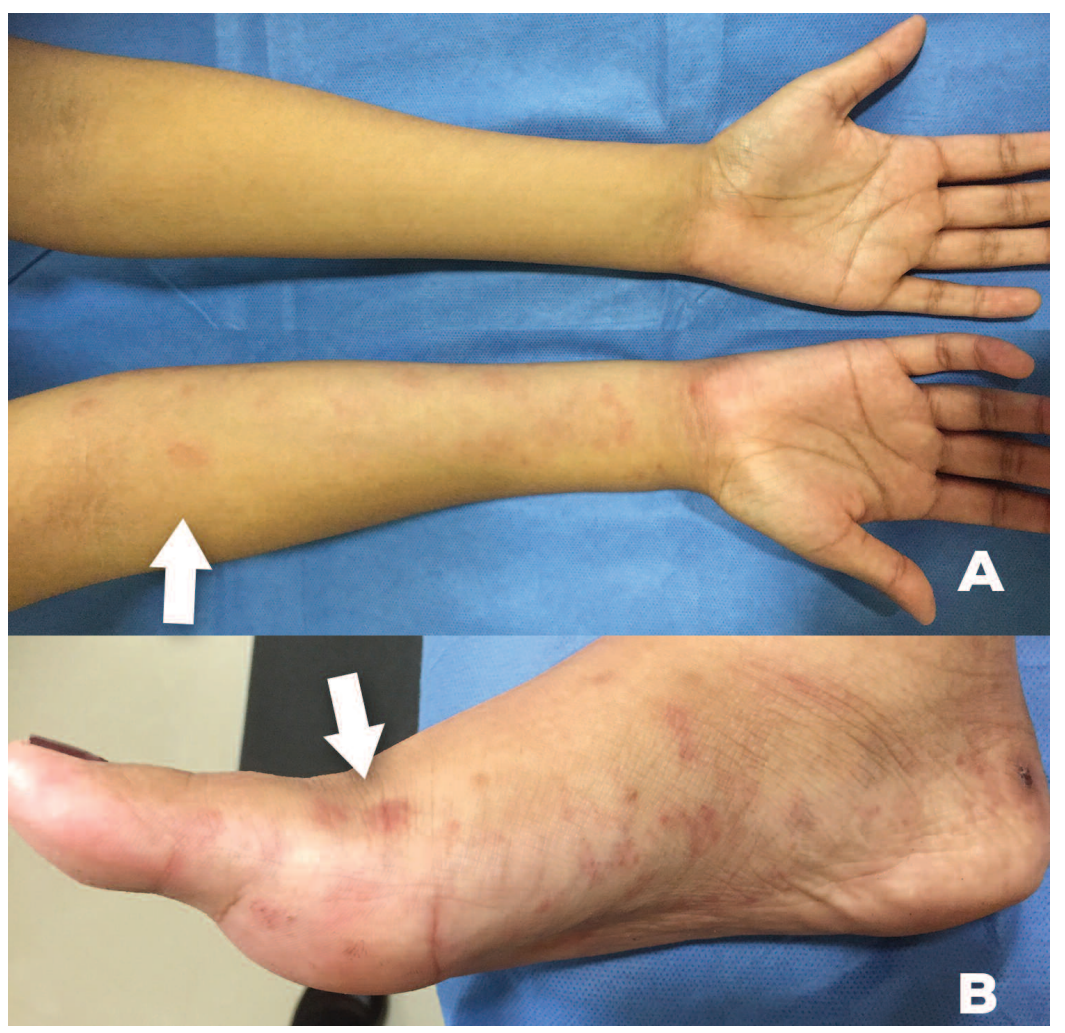

Figure 1. Hyperpigmented macules on the (A) upper and (B) lower right limbs (arrows).
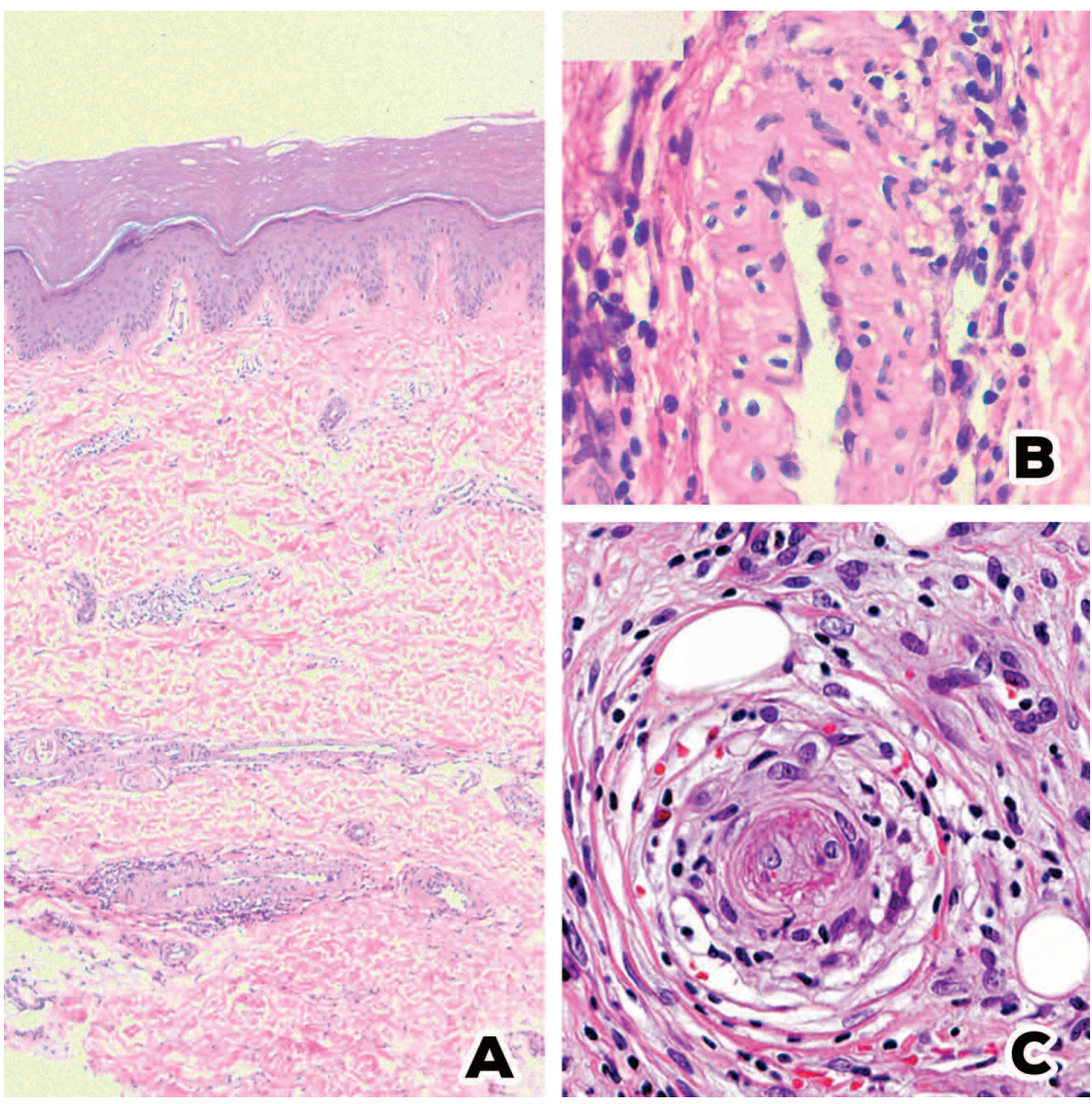

Figure 2. Skin biopsy with lymphocytic vasculitis (A) Lower magnification of the skin biopsy. (B and C) Perivascular inflammatory infiltrate affecting the arterioles mainly composed of lymphocytes, polymorphonuclear, and eosinophils. 